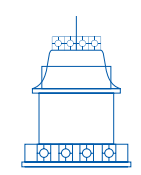

DOSSIER

\title{
Can there be an input from philosophical debates on a better use of nature? Towards an improvement of nature rights in environmental economics ${ }^{\star}$
}

\author{
Ernst-August Nuppenau \\ Justus-Liebig-Universität Giessen, Giessen, Germany \\ E-mail: ernst-august.nuppenau@agrar.uni-giessen.de \\ Recibido: 9 de abril de 2021 | Aceptado: 15 de junio de 2021 \\ https://doi.org/10.17533/udea.ef.345881
}

\begin{abstract}
This contribution will deal with granting rights to nature. We will define rights of nature as a social process of creating institutions which are linked to philosophical discourses on perceptions of nature. The idea is to use different narratives in order to understand how rights of nature have been and can be accomplished/derived by humans. Then we will give hints for future directions of right detection embedded in eco-systems. We will specifically focus on the right derivation needed for contracting with nature. We take the beaver, the wolf and the black tern as examples and generalize on case specific findings. All of them need habitats and landscapes in which they can live. The message is that landscapes and habitats are part of rights of nature and that they must be also addressed beyond individual species. Additionally, we will use different strains of thought to get hints on a practical establishing of rights of nature.
\end{abstract}

Keywords: rights of nature, institutions, right assignment

* This article is part of my personal work in the Justus-Liebig-Universität Giessen.

\section{Cómo citar este artículo}

Nuppenau, E. A. (2022). Can there be an input from philosophical debates on better use of nature? Towards improved nature rights in environmental economics. Estudios de Filosofía, 65, 31-48. https://doi.org/10.17533/udea.ef.345881 


\section{¿Puede haber una aportación de los debates filosóficos sobre un mejor uso de la naturaleza? Hacia una mejora de los derechos de la naturaleza en la economía medioambiental}

Resumen: Esta contribución tratará sobre la asignación de derechos a la naturaleza. Definiremos los derechos a la naturaleza como un proceso social de creación de instituciones que están vinculadas a los discursos filosóficos sobre las percepciones de la naturaleza. La idea es utilizar diferentes narrativas para entender cómo los derechos de la naturaleza han sido y pueden ser realizados/derivados por los humanos. A continuación, daremos pistas para futuras direcciones de detección de derechos integrados en los ecosistemas. Nos centraremos específicamente en la derivación de derechos necesaria para contratar con la naturaleza. Tomaremos como ejemplos el castor, el lobo y el charrán negro y generalizaremos los resultados de cada caso. Todos ellos necesitan hábitats y paisajes donde vivir. El mensaje es que los paisajes y los hábitats forman parte de los derechos de la naturaleza y que también deben abordarse más allá de las especies individuales. Además, utilizaremos diferentes corrientes de pensamiento para obtener pistas sobre el establecimiento práctico de los derechos de la naturaleza.

Palabras clave: derechos de la naturaleza, instituciones, discursos sobre la asignación de derechos

Ernst-August Nuppenau studied agriculture and economy at the University of Kiel (Germany). PhD in agricultural sciences at the University of Kiel. He has been a visiting researcher at Zimbabwe and Wageningen Universities. Since 1999 he is professor at the Justus-Liebig-Universität Giessen (Germany) of "Agricultural and Environmental Policy". 


\section{Introduction}

This contribution aims to shed some light on current and potentially improvable ways of assigning rights to nature. The analysis shall deliver an input to conflict resolution and possible behavioral change with regard to nature conservation. We will start with a problem statement on (1) why at present nature is detrimentally perceived as a competitor for land; then we will outline why (2) resource use as well as exploitation of nature prevail, and (3) a purely stated objective in terms of offering services as well as inputs for the human living are relevant issues in the ecological crisis, humans face. Specifically, we will outline why our current use of natural resources leads to over exploitation and loss of ecosystem functionality, i.e. if minor rights are involved. We will argue that nature is no longer a provider and right holder, hopefully resulting in the reduction of naturally generated services that can be used as inputs in the future; it rather has a poor position in society. (4) We suggest that a more partnership oriented interaction with nature, based on diligent rights assignment, may help to create a better state for both humans and nature. The discussion on survival and functionality, partly phrased as a philosophical question, shall go beyond a simple version of stating criteria for coexistence; again, rather it shall deliver the ethical background for collaboration between humans and nature with the common goal to maintain life on earth.

We see a globe, which is worth living in. The aspect of a better future for both humans (a species, which claims to be rational) and nature (a conglomerate of species, which is asserted as instinct driven) needs to be readdressed. We will do it in the vein of means and ends (reasoning, Zweckrationalität in German), objectives (philosophical foundation) and by offering a debate on positive and normative questions (ontological aspects). Hereby, we follow the philosophical idea that nature is ontologically considered a subject, which can have rights, and that (in conflicting cases as well as cases of needs for conservation) nature can outcompete human interests. We will look into that issue towards the questions: Why, when, and how do we need rights?

The role of nature in science has been traditionally considered objective vs. subjective, i.e., binary: either scientifically researched pure causality and deterministically driven by natural forces or researched more philosophically and socially as living organism (Sheldrake, 1996). This role has implications for assigning rights, so we will provide some arguments on why and how assigning rights to nature is needed by humans. The need for rights is given if conservation is the goal and a type of contracting with nature emerges (Serres, 1995). Though we will argue functionally (teleonomy-wise and not so much teleology-wise), we are required to open nature for subjective characterization. The argument for rights of nature and departure from pure science goes in the direction of grounding the issue for contracting with a subject (Nash, 1989; Serres, 1995). 
The intention of this contribution is to put resource users, especially land users and farmers, in a position where they have to investigate the "interests" of nature. Interest assigned to a subject is a process in social life (also in social science), and it is needed for contracting. In order to come up with a contractual perspective which humans usually are knowledgeable of, nature has to be made a subjective entity (with rights) which additionally can express its interest in the social process of finding solutions for survival and coexistence, notably to be initiated by a community or a government. Especially if contract making with nature is a future way of conservation, terms and conditions as well as rights are to be known for enabling specific contract making by parties.

Finding nature's rights, norms and conditions for contracting can be pursued as a game, consisting of making decisions on what to offer, accept, and how the contracts are specified (Binmore, 2005). Yet, a game approach has some philosophical background on fairness, rights, justice, etc. It tells us also in which field of interest and space we work; here we will refer to landscapes. We will lay the ground for such thinking and transfer the idea of rights and contracting to an anticipated nature, which is an entity of thought for humans and not to be seen as a resource only. In order to achieve more insight in the roles of humans and nature, we must discuss how subjects of nature (species) can be given thought and interest (provisionally); i.e., in a specific context understood as conflict area, for which we identify land use. We will argue "as if" nature has "interests" (for example in survival, but also in proliferation), and show how humans must include nature's interests in the formulation of action and in behavior.

The contribution follows a classic structure: first, with respect to making progress, some remarks are made on the state of debate; then we deliver arguments for the need of rights of nature in environmental economics as social science and finally we will make some suggestions on improvements and for setting of rights to nature as compared to the status quo. The emphasis lays on inclusion of landscape as an intermediary. The idea of the paper requires us to provide some insight in referenced reading of institution economics for rights and norms. The line of argumentation, though, is limited to coarse ways of understanding ethics and moral thinking and it regresses points on fixing rights to beliefs and behavior as in practical life. Admittedly, the analysis does not cover the "rights" discourse in-depth; rather we pick what is needed to make arguments to integrate landscapes as an intermediary for rights definition. This approach is dependent on urgent requirements for an institutional setting in which the humans have an object of nature understandable to them. We will start with selected species and then extend to habitats, which are landscape related. The hypothesis is: nature must be treated as a relevant normative entity in space; i.e. only if habitats are involved, land users will recognize nature rights, and thus they become functional. 


\section{Problem statement}

There are four strains of thought on rights for nature. They are mainly related to specific and selected features of nature being a living organism and a resource of living for humans. To understand the strains, the corresponding philosophical background has to be elaborated. (1) Opening the discourse, the ethical aspect has to be mentioned as humans want norms (perhaps with the exception of modern libertarians). For example, Nash (1989) gives a good overview on ethics and norms. He explained that a history has evolved which sees nature as equally recognizable in ethics as humans and that freedom for humans does not mean to harm nature. The authors in this sphere see rights (though initially used as a term for human rights) as expandable to living creatures and they try to find arguments for them. Also, they put animals and plants as well as eco-systems at the same level of recognition as the "social" entity of humans. Furthermore, a full strain of environmental ethics exists and is accessible in numerous publications (Quilley, 2009). Quilley, for instance, argues similarly to classical ethics that inter-subjectively one can find rules for treating nature well (hopefully healthily) to the extent that humans may suffer instead of nature. i.e. in case of conflict, it is not evident that only humans should survive, just to be straight, but humans may take burdens.

(2) The underlying paradigm is that rights are derived from needs for survival, given in a system of living organisms, and rights can be enforced if institutions recognize them. Institutions should evolve to protect and keep humans from negatively interacting with nature. Furthermore, rights evolve on the basis of thinking and they are part of a civilization process. The more biologically "enlightened" fraction in the debate (Moline, 1986 on Leopold etc.) sees rights as a platonic given structure, which needs to be discovered. In that philosophy, humans have to learn about rights of nature, i.e., as part of a moral community including other organisms. In the same direction of linking ecology, ethics and culture, Hanna, Folke \& Mäler (1996) argued for rights of nature as historically expressed by humans, though these authors already have an emphasis on implications for institution building in communities. (3) Actually, one can find many practical examples of how communities have addressed conflicts and elaborated pragmatics in assigning rights. These rights, found in real life, are very much expressed by common, normative customs. Though philosophical questions are embedded in practical solutions many times, it is sometimes difficult to infer them on basis of deliberations, rather they are customs. This means getting community thinking and backing linked to customs, taboos, community checks and controls, etc.

(4) Besides trials of explaining rights of nature against ethical conflicts, culture, customs, etc., we see a novel approach of founding through/on the basis of ecological reasoning. Biologically justified regulations on human excess and intrusion into nature's "world" have gained interest in the last decades. The way we receive goods and services from nature has received attention as norm and regulation setting. At the same time, it 
emphasizes conservation. Hence there is the rational that providers must have rights enabling persistence; Lauer (2016) sees giving as core and puts philosophical positions forward, which tell us how generous nature is. But, the generosity of nature as another synonym of ecosystem services cannot be expressed/understood scientifically only. The questions is: what rights and reciprocity issues emerge if we speak of gifting of nature?' However, transferring the idea, let us merely recapitulate: as a major question in human organization we have to know who has rights and it has to be cleared who has, for example, access to a good. Usually the one who has produced, cached or hunted it; and does this apply also to gifts? We face the problem that rights are to be grounded. Furthermore, how is responsibility and pertinence related to gifting? For example, any elite may live from the work of the folk; but it has to assure order. So, we have reciprocity involved.

Yet, are humans assuring order in the interaction with nature? What is their role in socio-economic systems? Do these systems need regulations and order, etc., which may give us hints on rights? The common argument in the political economy and science of rights, is that contracts are the immediate follow-up of avoiding open access regulations (Libecap, 1990). These regulations of rights show and establish a specific order which has to be understood.

However, as access to resources needs regulation (Prasad \& Tisdell, 1996), distribution of rights is what emerges first and is mostly argued with efficiency of right assignment. Maybe the functional argument of efficiency is one of the major driving forces for allocation of rights (hopefully, because power might be another one). From the underlying perspective of rights as creation and recognition, the many assignments of rights (to different groups: landowners, loggers, etc. for extraction; but also nature for conservation) are embedded in livelihood assessments and then biology becomes more meaningful. Yet, livelihood and survival are an aim and aims need justification. There is a need for arguing who shall survive and arguing is a typical philosophical way of establishing positions (note law has similar ways of justifying positions). The issue remains whether rights are apodictic or if they are functionally founded, in which case it means that the aims, interests, and results (means and ends) matter.

\section{State of the art}

One can also argue aims are established per se. For economists it is frequently efficiency (income, utility, food, insurance, etc.); for biologist it is conservation (biodiversity, climate, biospheres, habitats); for social scientists it is societal stability (classes, culture, etc.). Does this tell us something about rights? Rights for nature are no exception; they

1 It is not the job here to replicate the many deliberations already done, for example by Locke, etc.; see Lustig (1995). 
must be justified with argumentation and follow a doctrine of justification, which has a universal feature (per se). This "per se" is usually either religious or philosophical. Referring to the traditional total entity (god) in religion or the modern total entity (nature), rights systems are embedded in ways of thinking on how to achieve them. The same applies to resilience, resonance, and legitimacy. Taking this into account and asking if legal structures evolve under scarcity (Smith, 2002), the question is: is there a scope for prediction of rights for nature under the idea of "natural" (per se arguing)?

Additionally, though not as a real strain of thought for rights of nature, we can add modes and processes of finding rights. Rights and needs for rights are sometimes the consequence of interest modelling. (5) Interest modelling depends on individual and collective action; it has to be understood as the outcome of structured or un-structured processes and game type of thinking has contributed to supporting the processes. Rights must eventually follow the structure of a game; naturally or artificially introduced in the models, which enable later the interest games.

One structure is an awarding system for cooperation. It can be questioned whether humans are willing to co-operate with nature without incentive structure. There is the dispute. Most people in game theory work with the selfish actor. However, as put forward by Schüßler (2000) the argument on self-interest can be abundant in favor of a community interest if one works with the philosophical thinking of Spinoza. The argument is supported by special outlays of games in which the partner is "recognized" as relevant for wellbeing, i.e. if both sides (humans and nature) control contributions and have minor fears, uncontrolled forces diminish and communality enforces cooperation. Such processes mean creation of cooperation and right structures simultaneously. The structures are reciprocated and driven by reasoning not interest (selfish). There is a scope in which "communities" of humans evolve (dynamically) with other species leading to rights and responsibilities at a level of non-selfish/empathic/altruistic interest recognition. However, we must identify what drives interest and cannot solely rest on monetary interest of humans and need guides for conservation. Wording for resilience, restoration and reciprocity with nature are at different levels of cooperation and are of interest. Not even gift giving is sufficient as a concept because there is no pure gift giving in systems when it comes to viability and metabolic stability of systems; rather there must be adds for the higher-individual organizational structure.

Moreover, as the discussion of legal aspects and human rights to nature (Raftopoulos \& Powska, 2017) shows, there is a long tradition of relating rights of nature to protests of communities, mostly indigenous. For instance, in Latin America the relationship between communities and ecosystems has a long tradition, even from a bio-cultural perspective. Next, there is a tradition of tracing back eco-system services to, for instance, the philosophy of Aldo Leopold (Spangenberg et al., 2014) which says that humans can see nature as partners. For the exchange eco-system service as evolved are the research paradigm. There are attempts to anchor eco-system services in motives 
for landscape preservation and gain reciprocity; but mostly "well-being of humans" is referenced as being subject to exchange and forms humans' perspectives on rights and communality in aims of the system. However, from a more philosophical perspective, there is a missing link between the right for existence as coexistence and the scientific delineation of processes in nature operating at landscape level and integration.

About the scope of newly integrating strains of older philosophical thoughts in nature assessment, as well as the finding of directions for practical design of schemes in nature protection (aims), one should be reminded that there are concepts like the "sophia" and "practical philosophy" approaches which can be traced back to the Greeks thinking and other cultural paradigms, like for instance in China. ${ }^{2}$ Also, Yang \& Li (2016) stress that "design with nature" offers insight into debates on the role of nature (rights) and ecosystems beyond exclusive human derivation of aims; yet important in philosophical debates, the origin of aims in practical cases matters, but also the reasoning for it. This goes in line with the philosophy of Spaemann and Loew who claim that teleological thinking will be fruitful for science and societal debates and approaches for conservation. However, one has to admit rights of nature need system specific derivations in elaborated contexts and this contribution is an attempt to deal with farming and landscape systems as contexts for settling rights of nature.

In the next section we will make some predictions on future development/evolving of rights of nature and embed them into a landscape-oriented system of land use versus the current individual farming, which is a pure input-output system in food production. We will give examples of three types of animals which have rights: beavers, wolves, and birds. The issue, as compared to the current system where almost every interest is emerging from human rights, is whether we can find an ecological reasoning for establishing rights. The new system shall not be driven by rational/constructed currencies (monetary, human reasoning only and as currently done by monetarizing of nature and eco-system services through preference function approaches); rather that humans accept a reasoning founded on nature's interest, which is dependent on the functionality of nature; yet as an exchange system of matter (organic/inorganic) and energy.

\section{Evolution of rights for nature described by cases}

The four strain of thoughts mentioned principally for the development of nature rights will work together forging new rights, that is (1) ethics, (2) rights as force in biology, (3) culture and community, (4) economically assigned institutions, they will work together forging new rights. We try to exemplify connectivity. Additionally, in (5) we mentioned

2 For practical design questions see Xiang (2014) and the referenced literature. 
some modelling aspects to get predictable results. In the frame of causality and making sense of prediction by causes, strains (1) to (4) are forces and we either give study cases or say how forces work together universally, but that is difficult. Maybe cases cannot serve as blueprints, but they give insight. It is believed that methodologically one can learn from cases and then transfer them to usually more complicated ones.

In this paper three cases are examined under the assumption that landscapes matter because rights for species evolve within them. The first case shall be the reintroduction of the beaver in remote parts of Europe (especially Germany), where we observe minor conflicts. It is already quite successful, and we should learn the linkage between upstream argumentation and the introduction of rights for beavers. The second case is the wolf which in European areas so far designated to farming as priority, creates problems in intensively used farming areas and landscapes of pasture and cropping (especially in sheep rearing areas). There we see major tensions. In both cases we will report the current debate with respect to the four strains of thought from above connecting it to Aristotle that rights are interacting with actors, their intention and options. The third case is the merging issue of extinction of birds living in habitats which need high reconversion of farming. This is less striking but reveals deficits in the public debate.

\subsection{Beaver}

In the debate on reestablishing beavers and assigning them territorial rights (Gamborg, 2001) we can find detailed arguments which relate to the reasoning of having them in a landscape. There seems to be a consensus that beavers are to be protected because they are part of a nature, which delivers eco-system services and hence they are part of functional living landscape. The conflict with other land users is minor, because lands are usually confined to wetlands, which are less attractive/profitable to farmers. The beaver is largely given a function in eco-systems of water regulation and the land users seem to accept a right of coexistence for getting that service. Relating to the five categories mentioned, functionality of beavers in the eco-system also offers an entrance for ethics, culture, biology, and economics because interests are not too separate. This can be expressed in debates which offer arguments for the function of beavers and their habitats; and we see them confined to small areas in planning. There, beavers created their own habitat and the only problem is overpopulation, which needs control, perhaps as an agro-ecological approach. Furthermore, the case of rights for beavers tells us that the animal is not really a "dangerous" animal (instead people find their appearance appealing); there is sympathy and campaigns are appreciated by the public. This reduces power of resistance of land users in a game framework of finding compromises. Also, the beaver dwells mostly in extensively used landscapes in which few farmers make a living and land is not too scarce. On the 
side of philosophical arguments, the assertion is that not much reasoning is needed. Because the biology of the animal is understood well, by most people being involved in foraging, dwelling, and even hunting alike, the beaver is an easy right-holder. Also, it is clear where he lives, this species is recognized in the biological sphere, and humans feel no danger in terms of attacks.

\subsection{Wolves}

Concerning wolves, the conflict is much harsher, especially with respect to danger for livestock and animal rearing under natural pasture conditions (Meriggi \& Lovari, 1996). Yet, it is an old conflict and the ethics about coexistence are challenging. Biologists are excited, but they also receive much headwind. Because pastoralists show dead animals and animal rights seem to be doomed, there is an ongoing problem in fine-tuning which can be reckoned as a game for finding a suitable jurisdictive structure. Yet they shall be scientifically and philosophically based, at least in the wish of rationally declared agents and people in charge struggle finding easy rights. On the other hand, culture has shown compromises and we find some respect of "rights" (Dorresteijn, Milcu, Leventon, Hanspach, Fischer Ambio, 2016) formed historically. At the level of rights setting, ending in the design for practical institutions and regulations, it is difficult to follow the Kantian proposition of generalization as well as getting a "Golden Rule". For instance, the question is asked whether humans are predators in the biological sphere and should coexist with wolves and vice versa.

Another issue is pain or suffering in the sense of Bentham and Schopenhauer (McIntosh, 2010) which asks if humans suffer from wolves and vice versa, if wolves suffer from humans. Here the question is: where do they live together and who forages on what in the landscape? The interesting aspect is the contribution of landscape. Does the design contribute to suffering which can be reduced, for example for coexistence? The costs of buffering and zoning respectively are pertinent for separating wolves from humans and distract reasons for unnecessary extra-suffering. The rights and ethical problem of coexistence involved require seeking solutions to minimize the danger to each other. The goal is inferred from deliberations on utilitarian (Bacon) or transcendent (Kant) thinking. For the utilitarian one can again reference to the function of wolves. In that case the argument is that wolves, in a social Darwinist sense, kill only weak domestic sheep and the natural selection will guarantee survival of the system. In that case, weak sheep should be raised in buffer zones offering "prey". In the Kantian version wolves and sheep are part of a life-balance which is "natural", and they are compassionate in a sense that either wolves suffer because they have no food, or sheep suffer because humans do not protect them sufficiently. Only minor shares of herds are taken by wolves if humans make extra efforts of protecting their domestic animals. Equivalently the way of killing matters and humans should not keep large herds that are 
easy prey for wolves. Domestic sheep should have chances to escape and the rearing and management of animals' matters.

In this frame, rights for nature have other connotations with respect to human actions. Because animal rights can be defined differently to types of animal rearing and landscape management, here as means of mitigating conflict, rights are not exogenous; rather they are embedded in a deliberation of management and human goals. Rights of and on nature evolved equivalently if we look at costs in the utilitarian sense. There are landscapes which have lower stocking, and wolves will have costs to pursue prey from domestic animals as compared to dense rearing. In higher stocking areas of domestics, wolves will find it easy to prey on sheep. Hence they will have no free-ticket and numbers might be limited.

\subsection{Black Tern}

The Black Tern is a rare bird species and it needs special wetland habitats (Tozer et al., 2018) and the species population has declined rapidly over the last decades (van der Winden \& van Horssen, 2008). A population model for the black tern is envisaged. It is endangered because farmers have developed land for higher productivity, especially reduced water tables for dairy cows. The simple version of claiming a right, which would mean that the corresponding habitat has to be maintained, does not work. But, how can a bird have a right to habitat? For rights of nature and their implication, in the context of environmental economics in which economic activities (dairy) are focused, the request of a holistic approach appears. Again, this approach is linked to management, now at a defined landscape type (fens, marches, ditches, etc.). At this level, it is a frequent phenomenon that economics enters philosophical and rights issues. The term right, in its close human determination, is very much related to individuals and perhaps groups of a society, but not habitats and types of farming systems. Extended to nature the first thinking might be the extension of rights to other species; but now a farming system is asked for, which is strongly animal oriented. Farmers have to give up much of their "rights" which the acquired by new techniques. At a newly emerging need and level for giving nature rights, as a whole right, it is fairly ambitious asking farmers to give up rights at large scale. Yet in a world of conflicting interests with humans, mitigation is needed.

Without including legal aspects (Smith, 2002), a nomination problem is to define boundaries and fine-tune them. This is part of rights definition. As in the case of a rare bird species which lives in small colonies and relies on nesting, foraging and safety conditions in an open landscape (such as a wetland), the discussion on animal rights is a long list. But there is also active obligation mirroring rights. However, the obligations for humans (which come simultaneously) must be embedded in an understanding of the population dynamics even as habitat size definition is unclear. Additionally, there might be other birds as by-product-distortion which become 
abundant because they are also protected. Furthermore, high bird populations can attract predatory animals like foxes, etc. Again, we have a complex case in which rights are not independent from management, technology and they are also economically challenging. In addition, the size of habitats/landscapes and their interaction with the rest of ecology matters.

\section{Generalization}

\subsection{Getting rights}

By this observation one can, for the moment, conclude that rights of nature need active involvement of humans that have an idea of both goals and management options for nature conservation and functionality of ecosystems; also, provision of ecosystem services must be understood. Ecosystem services, reciprocally, are part of anticipated human exchange. Then, the experts additionally need to know what results in protection can be achieved and where results (for instance in a landscape) can be expended, i.e. at which places can interventions and gifting by nature (enforcing rights) result in which proliferation of populations. A question is: where is conservation most fruitful and which area could be left to human-centric use?

As we have had a focus on nature rights, which are assigned to propagate ecosystem services in landscapes, the issue of property rights and possession must be clarified (Steppacher \& Gerber, 2012). This distinction matters with respect to exchange and trade very much. Property as a right for nature would be possible at the level of issuing licenses for exclusive use. In this case commodification of nature could be made "perfect" and a market for nature would be the result. However, nature cannot be commodified and it is more conducive introducing possession as concepts. For instance, a possession system of rights means that humans and nature interact at the level of recognizing obligations if resources are diverted from nature for human use. The practical philosophical problem is which obligations shall be linked to extraction rights and how does it relate to the survival of species, but this is insufficient. Cases for example of beavers, wolves and black tern show that there are major differences in the arguments, management options and results. Following Bromley (2012) a right and obligation structure needs to be established as a public consensus, which is not fore-handedly provided from the outside, but must fit to the case. For example, nature conservation should not create privileged individuals in use of the resources or give individuals extra rights.

In a semi-natural landscape, for example, a beaver population offers nature made wetlands and a community of farmers and nature conservationists can find joint criteria on where to tolerate and where to extract beavers, if they create larger damage to the farming community. In that case the functional or possession rights for participants 
are to be built on a consensus where damages are occurring because of envisioned overpopulations of beavers. In that respect a "common" rule may be suggested, for example, such as a certain population density of beavers along a creek shall not be exceeded. Notice that hungry beavers venture into farmland such as maize fields and cause major damages. Yet there is a need for a cap in nature rights, which in the opinion of the author, has to be specified at landscape level. Is it a matter of pre-negotiations between experts and farmers to determine a tolerable level? Indeed, there is a need for consensus and eventually compensation payments borne by the government on the basis of local taxing of beneficiaries. Notice the beaver was introduced as an example for an "easy animal" and consensus can be reached without referencing to deadly encounters with humans as is the case with wolves. Also, the beavers' function in the ecosystem is relatively transparent, as is the benefit to humans (consumers of "in-tact" water and nature), which will only be argued by those bearing related opportunity costs (i.e. local farmers).

\subsection{Discussion for additional philosophical insight}

In the case of wolves, the moral problem is a bit more complicated. Wolves as predators are dangerous for pastoralists and their animals. Their function as controller of animal health (selection of sick animals) is difficult to understand and usually, in the discourse, there is an emphasis on moral aspects as if preferences matter. However, the problem entails that wolves kill sheep and hence sheep suffer, while the job of humans is to avoid suffering if they have committed themselves to rights of species (Anderson-Gold, 2001). Biologists may feel less bounded to philosophical questions of normative aspects in science and argue wolves are part of nature and from this observation they detect an immediate conservation category (though it runs against the philosophical notion that norms cannot be retrieved from causality: the natural fallacy). Retrieving generalized norms, which allow a discourse and justification of animal rights in terms of reliability and logical consistence, is difficult. To break it further down, there is the opportunity of taking the notion of inhabitance rights linked to typified landscapes (savannah, rain forest, etc.) and then prey and predatory animals inhabit the landscape. In this view the fundamental reasoning about a landscape is: there is a right for any species occupying a niche that corresponds to its function. At least one can understand morally that humans in this case will accept that provision is mutual because they are part of ecosystems. Then wolves should be given sufficient territory for pursuing their hunt for food (prey) in semi-wilderness.

In case of conflict, one could argue that a wolf can be gunshot if he (personalized) is not fulfilling a prescribed role (niche), i.e. if the wolf kills domestic animals simply because they are easier to catch than wild species, such as sick deer, he has to go. This super moral (beyond humans) is not teleology, rather teleonomy; i.e. wolves in their 
behavior and function should exist to select sick prey along a "natural" mode. This "law" (nomos) usually forces them to use wild animals and stay away from domestic animals and humans; it is part of fulfilling one's role (niche) in nature. This is only possible in a landscape designed along a provision of corridors or elements separating the spheres of humans and wolves; i.e. mostly if natural elements are maintained. Vice versa it tells humans don't intrude in wolves' territories. Apparently, many questions are popping up. One immediate question is about population density and obligations of humans for controlling even their population as well as declaring areas in which humans exclude development. We can express wolves' rights in the possession of land shares. It forces humans not to intrude into semi-natural territories, though they live close and control their expansion.

Now, a notice on emerging rights and compliance is needed: as usual rights are either informally respected as part of culture or formally written in laws as well as restrictions and are authorized by governments. In special cases, legal procedures may apply, but in day-to-day operation informal rights usually matter and the way the wolf is operating has an impact on "feeling" rights. Next, for the conflicting issue of killing of domestic animals the wolf must eventually take a "responsibility", which has to be "taught" to him. Emotions and practical things count. Practical examples are electric fences, etc. (there is a right of information before killing in the case of incidences of transgressing territory of fences). Then a question is "what is natural" and how does animal behavior matter? The author thinks that "killing" is natural for the reason of survival, not for convenience. Such deliberations may matter in public discourses and disputes.

For the black tern case we foresee a further escalation in rights to landscapes and their design. For the survival of this species (here at a peninsula of Germany, Eiderstedt) it is necessary to re-convert the landscape, which has previously been drained into a special type of grassland (instead of wetland) for intensive cattle rearing. Nowadays it is a "new" landscape with ditches, deep drainage canals; not overly suitable as habitat, etc. The current landscape refers to a farming priority in which "high quality" grassland supports high density of dairy cattle, where grass and silage making dominates. (However, in the old, traditional landscape there were habitats for black tern because of extensive grassing and minor drainage). Since nowadays the landscape primarily serves commercial farming and business objectives, the bird is endangered. It might be argued that in a cost-benefit-analysis the government will find out that the bird is not "paying off" anymore and no need exists for conservation (respectively costs are too high if farmers reconvert their land to extensive grazing and shallow ditches instead of deep canals for drainage, etc.). So what is the role of landscape (design) and bird (protection)?

Starting from a different angle for generalization, which sees intensive farming as an opportunity and threat, not as a right per se; then such cost-benefit analysis becomes 
obsolete. It raises questions whether, in a society, any member has the right to pursue his interest or whether the society for a reason of coherence and conservation can restrict business. From the side of a Kantian approach in which nobody knows his position in society (veil of ignorance, Bromley, 2012), one can argue that the right to convert a landscape which has been inhabited over centuries by humans and natural species alike is limited, and conversion needs reasoning per se.

Making a landscape a most lucrative business (from the monetary perspective) can only be justified if there is a commodity of "need" (Bromley, 2006) who distinguishes between needs as generalizable social objective and individual preferences as welfare when methodological individualism applies as sum of utility). At this level of justification (see black tern), the commodity produced (milk) and technology (drainage) matters, i.e. (1) is the commodity really scarce? In the case of milk one can argue: no! And milk can be produced elsewhere, eventually at equivalent costs. (2) Do we really have to support local farmers in sustaining their livelihood at such high levels of intensity? Answer: no! (3) Are there alternatives for farmers and can they be requested to be limited in farming in some areas, which reduces yields and requires more labor because less machines (extensive production) can be used? Yes! Mostly there are alternatives in feeding cows and there is no absolute need for modern technology of farming. Re-conversion of land for protecting birds in semi-natural environments is again referenced to landscape design; it is possible and land use change of the past can be returned (Schleupner \& Link, 2008). However, this usually creates big protests and endless discussions because it is said that governments interfere with the right to farm and even culture is inflicted adversely (Krauss, 2006), for example if people think their culture is dominant. Nonetheless, there is a right for habitat. In this regard rights, culture, regional identity, etc. become a matter of "philosophy" of living, distinctiveness, future, etc. and strong wordings are used.

So where is the way out? As rescuing of habitats for some opponents (mostly farmers but also tourist industries, just to mention current large-scale intruders) means giving up rights and vice versa, it is very important to construct a process of identification with protection of species and create new identities. In this respect, being frequently given the aim of protection and making it a branding for marketing, community identity has gained interest. Branding of the landscape (is?) popular. Such branding helps opponents change their opinion and see the advantages (Masden \& Smith, 2005) as well as become a member of a new community. It means they have a right for consultation and potential gains if there is, for example, tourism. Still, the advantages have to be shared, especially when it comes to tourism projects and new definitions of extraction appear. Actually there are cases where the reintroduction of birds (vultures for example) has attracted eco-tourism and the farming community gained (Stoynov \& Peshev, 2014); however, mostly in poor areas, while the conflict is prevalent in landscapes we now see "vulture lands". 


\section{Summary and conclusions}

This contribution dealt with rights of nature using three examples: the beaver, the wolf, and the black tern. It was argued that all lives and their rights are to be located in a landscape and this creates the need for a discourse on rights of nature in landscapes and habitat rights respectively. Since the definition of rights is a social (human) process that entails elements of institutionalization, we referenced perspectives of institution economics, which in turn have a philosophical background. This background was further explored by asking about conflict solving mechanisms. The idea was to get access to different narratives where species have a right alongside humans. The rights were outlined here within a more natural and multifunctional landscape approach.

\section{References}

Anderson-Gold. S. (2001). Unnecessary evil. History and moral progress in the theory of Kant. State University of New York Press.

Binmore, K. (2005). Nature justice. Oxford. https://doi.org/10.1093/acprof:0 so/9780195178111.001.0001

Bromley, D. W. (2006). The economic dynamics of environmental law. American Journal of Agricultural Economics, 88(3), 770-771. https://doi.org/10.1111/j.14678276.2006.00895_3.x

Bromley, D.W. (2012). Environmental governance as stochastic belief updating crafting rules to live by. Ecology and Society, 17(3), 1-8. https://doi.org/10.5751/ES-04774-170314

Dorresteijn, I., Milcu, A. J., Leventon, J., Hanspach, J. \& Fischer Ambio, J. (2016). Social factors mediating human-carnivore coexistence: understanding thematic strands influencing coexistence in Central Romania. AMBIO A Journal of the Human Environment, 45(4), 490-500.

Gamborg, C. (2001). Sustainability and biodiversity: ethical perspectives on forest management (PhD. Thesis). University of Copenhagen.

http://curis.ku.dk/ws/files/13035957/Christian_Gamborg.pdf\#page=146

Hanna, S., Folke K. \& Mäler, G. (1996). Rights to nature: culture, ecological economics, political principles of institutions for the environment. Island Press.

Krauss, W. (2006). The natural and cultural landscape heritage of Northern Friesland. International Journal of Heritage Studies, 11(1), 39-52.

Libecap, G. D. (1990). Contracting for property rights. In: T. L. Anderson \& F. S. McChesney (Ed.), Property rights: cooperation, conflict and law (pp. 142-167). Cambridge University Press. https://doi.org/10.1017/CBO9780511664120 
Lauer, C. (2016). Confronting the anthropocene: Schelling and Lucretius on receiving nature's gift. Journal of Comparative and Continental Philosophy, 8(2), 160-179. https://doi.org /10.1080/17570638.2016.1200317

Lustig, B. A. (1991). Natural law, property, and justice: the general justification of property in John Locke. The Journal of Religious Ethics, 19(1) 119-149.

Marsden, T. \& Smith, E. (2005). Ecological entrepreneurship: sustainable development in local communities through quality food production and local branding. Geoforum, 36(4), 440-451. https://doi.org/10.1016/j.geoforum.2004.07.008

McIntosh, D. (2010). The transhuman security dilemma. Journal of Evolution and Technology, 21(2), 32-48.

Meriggi, A. \& Lovari, S. (1996). A review of wolf predation in southern Europe: does the wolf prefer wild prey to livestock? Journal of Applied Ecology, 33(6), 1561-1571. https://doi. $\operatorname{org} / 10.2307 / 2404794$

Moline, J. N. (1986). Aldo Leopold and the moral community. Environmental Ethics, 8(2), 99-120. https://doi.org/10.5840/enviroethics19868222

Nash, R. F. (1989). The rights of nature: a history of environmental ethics. Madision.

Prasad, B. C. \& Tisdell, C. (1996). Getting property rights "right": land tenure in Fiji. Pacific Economic Bulletin, 11(1), 31-39.

Quilley, S. (2009). The land ethic as an ecological civilizing process: Aldo Leopold, Norbert Elias, and Environmental Philosophy. Environmental Ethics, 31(2), 115-134. https://doi. org/10.5840/enviroethics200931215

Raftopoulos, M. \& Powska, R. (Eds.). (2017). Natural resource development and human rights in Latin America: state and non-state actors in the promotion and opposition to extractivism activities. Denmark. https://vbn.aau.dk/ws/files/291002023/Nat_Res_ Dev_and_HR.pdf

Serres, M. (1995). The natural contracts. An Arbor. https://doi.org/10.3998/mpub.9725

Schleupner, C. \& Link, P. M. (2008). Potential impacts on important bird habitats in Eiderstedt (Schleswig-Holstein) caused by agricultural land use changes. Applied Geography, 28(4), 237-247. https://doi.org/10.1016/j.apgeog.2008.04.001

Schüßler, R. (2000). Zur konvergenz von moral und eigeninterresse. In: K. Hammacher, I. ReimersTovote, M. Walter (Eds.), Zur aktualität der ethikc spinozas. Schriftenreihe der Spinoza gesellschaft. Bd.7 (pp. 212-239). Würzburg.

Reimers-Tovote, M. Walter (Eds.), Zur aktualität der ethikc spinozas. Schriftenreihe der Spinoza gesellschaft. Bd.7 (pp. 212-239). Würzburg.

Sheldrake, R. (1996). The rebirth of nature: the greening of science and God. Rochester.

Smith, H. E. (2002). Exclusion versus governance: two strategies for delineating property rights. The Journal of Legal Studies, 31(2), 453-487. https://doi.org/10.1086/344529 
Spaemann, R \& Loew, R. (2005). Natuerliche ziele. Geschichte und wiederentdeckung des teleologischen denkens. Klett Cotta.

Spangenberg, J. H., van Haaren, C., Settele, J. (2014). The ecosystem service cascade: further developing the metaphor. Integrating societal processes to accommodate social processes and planning, and the case of bioenergy. Ecological Economics, 104, 22-32. https://doi. org/10.1016/j.ecolecon.2014.04.025

Steppacher, R. \& Gerber, J. F. (2012). Meanings and significance of property with reference to today's three major eco-institutional crisis. In: J. F. Gerber \& R. Steppacher (Eds.), Towards an integrated paradigm in heterodox economics. Alternative approaches to the current eco-social crisis (pp. 111-123). Palgrave. https://doi.org/10.1057/9780230361850_6

Stoynov, E. \& Peschev, H. (2014). Reintroduction of griffon vulture gyps fulvus in kresna Gorge of Struma River. Annual Report 2013. https://www.researchgate.net/profile/ Emilian_Stoynov/publication/269691140_Re-introduction_of_Griffon_Vulture_ Gyps_fulvus_in_Kresna_Gorge_of_Struma_River_Bulgaria_Annual_Report_2013/ links/5491b95focf269b048616b49.pdf

Tozer, D.C., Steele, O. \& Gloutney, M. (2018). Multispecies benefits of wetland conservation for marsh birds, frogs, and species at risk. Journal of Environmental Management, 212, 160-168. https://doi.org/10.1016/j.jenvman.2018.01.055

van der Winden, J. \& van Horssen, P.W. (2008). A population model for the black tern Chlidonias niger in West-Europe. Journal of Ornithology, 149, 487-494. 10.1007/s10336-008-0292-z

Xiang, W.-N. (2014). Doing real and permanent good in landscape and urban planning: ecological wisdom for urban sustainability. Landscape and Urban Planning, 121, 65-69. https:// doi.org/10.1016/j.landurbplan.2013.09.008

Yang, B. \& Li, S. (2016). Design with nature: Ian McHarg's ecological wisdom as actionable and practical knowledge. Landscape and Urban Planning, 155, 21-32. https://doi. org/10.1016/j.landurbplan.2016.04.010 